\title{
Comparison of Student and Faculty Perceptions of Team Performance in Capstone Design Projects as Evaluated by Graduate Attribute-Linked Rubrics
}

\author{
Antony J. Hodgson and Jon Mikkelsen \\ Department of Mechanical Engineering, University of British Columbia \\ ahodgson@mech.ubc.ca
}

\begin{abstract}
UBC's mechanical engineering program adopted a new evaluation format two years ago based more on 'design dossiers' than the traditional formal engineering report. The intent was to provide students with a more industrially relevant experience of generating technical documentation, in which documents are produced on a more continuous basis. Last year, we introduced an evaluation scheme based on rubrics. This year, we plan to compare student and faculty perceptions of team performance as evaluated by this rubric scheme. We expect to collect student evaluations from one third to one half of the class and will present our findings at the summer meeting.
\end{abstract}

Keywords: Dossier, rubrics, CEAB, graduate attributes

\section{INTRODUCTION}

Design dossiers and technical design files are universally used in engineering practice [1,2], yet the most common evaluation mechanism used in capstone design courses is the formal engineering report. Students often defer the writing of such reports until the deadline, which can introduce a significant lag between when the original activities occurred and when the writeup takes place. Teams often delegate the writing task to students perceived to be less capable of 'real' engineering work.

Such attitudes and practices run strongly counter to technical documentation expectations in engineering practice (particularly firms following ISO-9000-type processes), where engineers are expected to document their work on a continuing (and daily) basis in the form of design files or dossiers.

Two years ago, UBC adopted this approach for our capstone mechanical engineering design course. Last year, we described a new set of CEAB-attribute-linked rubrics we had created to improve the evaluation of design dossiers, particularly in the context of a multiinstructor scenario where it is important to provide consistent grades across disparate groups supervised by a variety of instructors. In this year's presentation, we describe our efforts to evaluate whether or not instructor and student perceptions of team performance are consistent with one another.

\section{METHODOLOGY}

During the 2012-13 academic year, we expanded the set of rubrics described last year and are using them more consistently across the five-member instructor team (responsible for 20-25 student teams; nominally 4 teams per instructor; one instructor had a double assignment). These rubrics address over 50 aspects of the design process, divided into 12 typical phases of the design process. Each rubric consists of a description of an attribute linked to the $\mathrm{CEAB}$ graduate attributes (including design-related sub-attributes), along with a description of typical artifacts (physical, virtual or documentation) students might be expected to produce in executing each phase. Levels of performance are described in three main categories: marginal, competent and exemplary.

In order to assess consistency of perception between students and instructors, each instructor was encouraged to use the evaluation rubric to assess each team under their supervision. The rubric itself was not directly used to assign marks, but to inform a cross-instructor discussion process we used to normalize expectations across the team. Teams were likewise invited to submit one rubric evaluation form on a per-team basis; participation was voluntary. To date, we have collected rubrics from approximately one quarter of the class and hope to obtain more in due course. By the time of the CEEA meeting, we will have analyzed these evaluation forms and will present data to test the hypothesis that student perceptions substantially match faculty evaluations when using these rubrics.

\section{Acknowledgements}

The authors would like to thank our faculty colleagues (Markus Fengler, Steve Rogak, Gary Schajer and Wayne Williams), as well as all our student teams, for participating in this rubrics assessment process.

\section{References}

[1] Hueta G, Culleya SJ, McMahon CA \& Fortin C. (2007) Making sense of engineering design review activities. Artificial Intelligence for Engineering Design, Analysis and Manufacturing, 21(3):243266

[2] Aitchison GA, Hukins DWL, Parry JJ, Shepherd DET \& Trotman SG (2009), A review of the design process for implantable orthopedic medical devices. Open Biomed Eng J, 3:21-27 